\title{
Distinct Postsurgical Management in Young and Elderly Breast Cancer Patients Results in Equal Survival Rates
}

\author{
Ebru Sen Oran², Yucel Yankol' ${ }^{2}$, Gursel Remzi Soybir ${ }^{1 *}$, Tamer Karsidag ${ }^{4}$, Onur \\ Sakalli $^{1}$, Umit Gecgel ${ }^{1}$, Onur Can Soybir ${ }^{5}$, Atilla Soran ${ }^{6}$
}

\begin{abstract}
Background: Although breast cancer (BC) is one of the most common malignant diseases in women, the majority of the studies describing the characteristics of $\mathrm{BC}$ in elderly patients have been limited to survival assessments or tumor features, without using younger $\mathrm{BC}$ patients as a reference group. The aim of our study was to describe and compare tumor characteristics and management patterns in elderly versus younger breast cancer patients in Turkey. Materials and Methods: We retrospectively analyzed 152 patients with invasive breast cancer who underwent surgery in our institution between 2002 and 2012. Patients were divided into 2 groups according to age at the time of diagnosis. Results: There were 62 patients in the elderly group ( $\geq 65$ years) and 90 patients in the younger group ( $<65$ years). Compared to the younger group, tumors in the elderly group were more likely to be larger $(p=0.018)$, of lower grade $(p=0.005)$, and hormone receptor-positive $(p>0.001)$. There were no significant differences regarding histology, localization, lymph node involvement, or types of surgical procedures between the 2 groups. Comorbidities were more common in elderly patients $(\mathbf{p}<0.001)$. In addition, elderly patients were more likely to receive hormonal therapy $(p<0.001)$ and less likely to receive radiotherapy $(p=0.08)$ and chemotherapy $(p=0.003)$. There was no difference in survival and locoregional recurrence rates between the groups. Conclusions: The results of this study demonstrate that breast cancer in elderly patients has more favorable tumor features, warranting less aggressive treatment regimens after surgery.
\end{abstract}

Keywords: Breast cancer - elderly - survival - recurrence

Asian Pac J Cancer Prev, 15 (18), 7843-7847

\section{Introduction}

Breast cancer (BC) is one of the most common malignant diseases in women and constitutes a major, worldwide health problem, with incidence rates continuing to increase (Malik et al., 2013). Moreover, age is a dominant risk factor in the development of BC. Approximately onethird of $\mathrm{BC}$ patients are women $>70$ years old, and half are $>65$ years old (Tipples and Robinson, 2009; Vrana et al., 2013). Despite the fact that $\mathrm{BC}$ is a significant cause of morbidity and mortality in elderly women, many trials on which clinical practice is based have been conducted in younger populations, resulting in an under-representation of older patients (Tang et al., 2011; Güth et al., 2013; Mohamed and Muhamad, 2013).

As the elderly population increases, the optimal management of BC in older women becomes an increasingly important issue. Although relatively little is known about possible differences in the biology of BC in older patients compared to younger patients, it has been reported that advanced age is associated with less aggressive tumor features (Tipples and Robinson, 2009; Tang et al., 2011; Thomas and Leonard, 2009; Wildiers, 2008; Rao et al., 2007; Thapa et al., 2013; Zhao et al., 2014). In addition, an understanding of the relationship between age and life expectancy is vital in making clinical decisions regarding treatment (Rao et al., 2007). The average future life expectancy of a 65-year-old woman is nearly 20 years and that of an 80-year-old woman is 9 years (Tang et al., 2011). Both reductions in life expectancy and an increased frequency of comorbid illnesses account for diversions in standard BC treatment algorithms in elderly patients (Rao et al., 2007; Wyld and Reed, 2007). Treatment-related morbidity plays a significant role in the application of curative treatment in elderly patients; older patients are more likely to prefer an improvement in their current quality of life rather than a potential increase in survival (Yellen et al., 1994). As a consequence, elderly patients generally receive less aggressive and intensive treatment (Vrana et al., 2013; Wildiers, 2008; Thapa et al., 2013; Molino et al., 2006; Phua et al., 2010). However, more than half of elderly BC patients are undertreated, 
Ebru Sen Oran et al

which significantly reduces their cancer-related survival (Wyld and Reed, 2007; Bouchardy et al., 2003; Bland et al., 1999; Yood et al., 2008). Accordingly, it is important to develop parameters that may guide the decisions of physicians and patients regarding the most appropriate treatment course.

Most studies describing the characteristics of BC in elderly patients have been limited to survival assessments or tumor features, without using younger BC patients as a reference group (Bouchardy et al., 2003; Pierga et al., 2004; Siegelmann-Danieli et al., 2009; Theriault et al., 2011). Therefore, the aim of this retrospective study was to compare tumor characteristics, patient characteristics, management patterns, and treatment outcomes between young and elderly women with BC at our institution.

\section{Materials and Methods}

\section{Patients}

We retrospectively analyzed all female patients with BC who underwent surgery at Istanbul Haseki Research and Training Hospital between January 2002 and December 2012. The study approved by the institutional review board. Women with ductal carcinoma in situ, stage IV disease, recurrent BC, and those who received neoadjuvant treatment were excluded. All patients who did not meet these exclusion criteria were included in the study. Patients were divided into 2 groups according to age at the time of diagnosis: $<65$ years (Group 1) and $\geq 65$ years (Group 2 ).

\section{Data collection}

Data regarding tumor and patient characteristics, management patterns, and outcomes were extracted from clinical charts. BC was histologically confirmed by core biopsy before surgery in all patients. All patients underwent either breast conserving surgery (BCS) or mastectomy. Axillary dissection was routinely applied to patients who had clinically or radiologically suspicious axillary lymph nodes or whose sentinel lymph nodes were involved.

Tumor characteristics included localization, histological type, size, grade, nodal status, and hormone receptor status. Axillary lymph nodes with more than $2 \mathrm{~mm}$ tumor invasion by histopathological evaluation were defined as involved nodes. Tumors were considered hormone receptor-positive if either estrogen or progesterone receptor was more than $10 \mathrm{fmol} / \mathrm{mg}$ or more than $10 \%$ of cells stained positive by immunohistochemistry.

Data on patient characteristics included all comorbidities, such as hypertension, diabetes, respiratory problems, and cerebrovascular disease. Postoperative complications that developed within the first month after surgery were also noted.

In order to evaluate management patterns, surgical and post-surgical treatments were recorded. Specifically, we collected information on the use of radiotherapy, chemotherapy, and/or hormonal therapy.

To analyze the outcomes of the patients, all local and regional recurrences and metastases that appeared in the post-operative period were recorded.

\section{Statistical analysis}

We compared both age groups in order to identify any age-related differences with respect to tumor and patient characteristics, management patterns, and outcomes using the chi-square test. Kaplan-Meier survival analyses were used to estimate disease-free and overall survival rates. Statistically significant differences in survival were determined using the log-rank test. In all analyses, a 2 -sided $\mathrm{p}$ value $<0.05$ was considered significant.

\section{Results}

Over a 10-year period, $152 \mathrm{BC}$ patients underwent surgery in our institution and were included in the study. Ninety patients were in Group 1 (<65 years), and 62 patients were in Group 2 ( $\geq 65$ years). The tumor and patient characteristics, management patterns, and outcomes of BC patients in both age groups are summarized in Table 1.

\section{Table 1. Patient Characteristics}

\begin{tabular}{|c|c|c|c|}
\hline & $\begin{array}{c}\text { Group } 1 \\
\text { Age }<65 \\
\text { years }(\%) \\
n=90\end{array}$ & $\begin{array}{c}\text { Group } 2 \\
\text { Age } \geq 65 \\
\text { years }(\%) \\
\mathrm{n}=62\end{array}$ & $\begin{array}{l}\mathrm{p} \text { value } \\
\text { chi-square } \\
\text { or log rank } \\
(*) \text { test }\end{array}$ \\
\hline \multicolumn{4}{|l|}{ Tumor Characteristics } \\
\hline $\begin{array}{l}\text { Localization } \\
\text { Upper Outer } \\
\text { Upper Inner } \\
\text { Lower Outer } \\
\text { Lower Inner } \\
\text { Central }\end{array}$ & $\begin{array}{r}54(60.0) \\
15(16.7) \\
11(12.3) \\
8(8.8) \\
2(2.2)\end{array}$ & $\begin{array}{r}37(60) \\
9(14.5) \\
10(16) \\
5(8) \\
1(1.5)\end{array}$ & 0.16 \\
\hline $\begin{array}{l}\text { Histology } \\
\text { Ductal Cancer } \\
\text { Lobular Cancer } \\
\text { Other }\end{array}$ & $\begin{array}{r}69(76.6) \\
13(14.4) \\
8(8.8)\end{array}$ & $\begin{array}{r}46(74.2) \\
8(12.9) \\
8(12.9)\end{array}$ & 0.72 \\
\hline $\begin{array}{l}\text { Tumor Size } \\
\leq 2 \mathrm{~cm}\end{array}$ & $54(60.0)$ & $23(17)$ & 0.018 \\
\hline $\begin{array}{l}\text { Grade } \\
\qquad 1,2\end{array}$ & $43(47.7)$ & $44(71)$ & 0.005 \\
\hline $\begin{array}{l}\text { Lymph Nodes } \\
\text { Involved }\end{array}$ & $49(54.4)$ & $33(53.2)$ & 0.70 \\
\hline $\begin{array}{l}\text { Hormone Receptor Status } \\
\text { ER or PR Positive } \\
\text { Patient Characteristics }\end{array}$ & $36(40.0)$ & $46(74.2)$ & $<0.001$ \\
\hline $\begin{array}{l}\text { Comorbidity } \\
\text { Yes }\end{array}$ & $26(28.8)$ & $35(56.5)$ & $<0.001$ \\
\hline $\begin{array}{l}\text { Postoperative Complication } \\
\text { Yes }\end{array}$ & $19(21.1)$ & $19(30.6)$ & 0.18 \\
\hline \multicolumn{4}{|l|}{ Management Patterns } \\
\hline $\begin{array}{l}\text { Breast Surgery } \\
\text { BCS (versus mastectomy) }\end{array}$ & $59(65.5)$ & $41(66.1)$ & 0.94 \\
\hline $\begin{array}{l}\text { Axillary Surgery } \\
\text { Axillary Dissection (versus no }\end{array}$ & $49(54.4)$ & $33(53.2)$ & 0.70 \\
\hline $\begin{array}{l}\text { Radiotherapy } \\
\text { Yes }\end{array}$ & $67(74.4)$ & $38(61.2)$ & 0.08 \\
\hline $\begin{array}{l}\text { Chemotherapy } \\
\text { Yes }\end{array}$ & $62(68.8)$ & $28(45.2)$ & 0.003 \\
\hline $\begin{array}{l}\text { Hormonal Therapy } \\
\text { Yes }\end{array}$ & $36(40.0)$ & $46(74.2)$ & $<0.001$ \\
\hline $\begin{array}{l}\text { Outcomes } \\
\text { Locoregional Recurrence } \\
\text { Yes }\end{array}$ & $25(27.7)$ & $14(22.5)$ & 0.47 \\
\hline $\begin{array}{l}\text { Overall Survival } \\
\text { Months }(95 \% \mathrm{CI})\end{array}$ & $\begin{array}{r}95 \\
5.3-106.1)(\end{array}$ & $\begin{array}{r}100 \\
(80.5-112.8)\end{array}$ & $0.61 *$ \\
\hline $\begin{array}{c}\text { Disease Free Survival } \\
\text { Months }(95 \% \mathrm{CI})\end{array}$ & $\begin{array}{r}74 \\
.2-100.6)(\end{array}$ & $\begin{array}{r}78 \\
(96.5-118.3)\end{array}$ & $0.31 *$ \\
\hline
\end{tabular}

ER, estrogen receptor; PR, progesterone receptor; $\mathrm{BCS}$, breast conserving surgery; $\mathrm{CI}$, confidence interval 
In general, most tumors were ductal carcinoma located in the upper region of the breast, with half of the patients showing lymph node involvement. The 2 groups differed in terms of tumor size and hormone receptor status. Only $37 \%$ of elderly patients presented with small tumors $(\leq$ $2 \mathrm{~cm})$, compared to $60 \%$ of younger patients $(\mathrm{p}=0.018)$. On the other hand, most elderly patients $(71 \%)$ were hormone receptor-positive, compared to $48 \%$ of younger patients $(\mathrm{p}<0.001)$. These data suggest that the tumor characteristics of elderly $\mathrm{BC}$ patients are less aggressive than those in younger $\mathrm{BC}$ patients.

The incidence of postoperative complications was comparable between the 2 groups, despite the fact that elderly patients were significantly more likely to have comorbidities than the younger patients $(\mathrm{p}=0.001)$. The most common morbidity in both groups was hypertension (Group 1: $n=15$; Group 2: $\mathrm{n}=25$ ) followed by diabetes mellitus $(n=12)$ in the elderly patients and ischemic cardiovascular disease $(n=15)$ in the younger patients. These data suggest that these comorbidities were not risk factors for postoperative complications.

There was no difference between the groups in terms of surgical management. Among all patients, BCS (66\%) was performed more often than mastectomy, and axillary surgery was routinely performed in all patients with suspected lymph node involvement. On the other hand, compared to younger patients, elderly patients were more likely to receive hormonal therapy $(\mathrm{p}<0.001)$ and less likely to receive adjuvant chemotherapy $(\mathrm{p}<0.003)$ or radiotherapy $(\mathrm{p}=0.08)$. Therefore, the administration of hormonal therapy in elderly $\mathrm{BC}$ patients is driven by a hormone receptor-positive status.

The different treatment courses adopted for young and elderly BC patients resulted in similar outcomes, in terms of locoregional recurrence rates (Group $1 \mathrm{vs}$

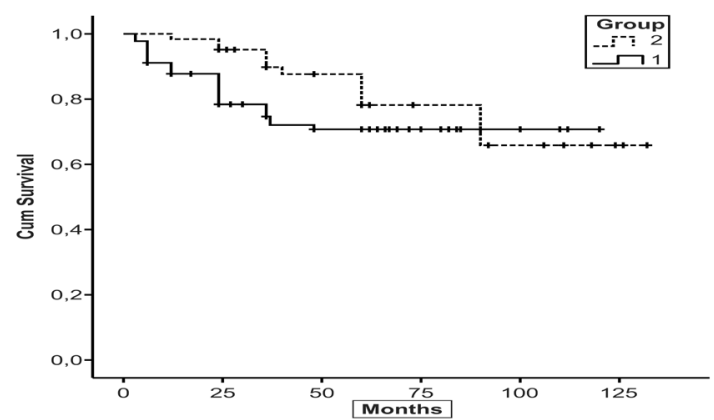

Figure 1. Disease-Free Survival by Age Group. Group 1 ( $<65$ years); Group 2 ( $\geq 65$ years)

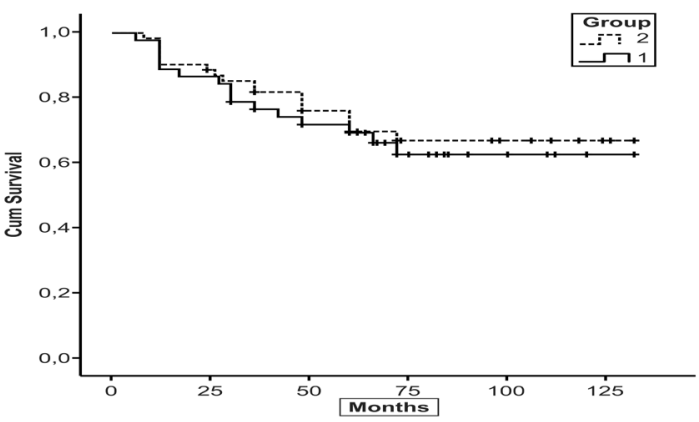

Figure 2. Overall Survival by Age Group. Group $1(<65$ years); Group 2 ( $\geq 65$ years)
Group 2: $22.5 \%$ vs 27.7\%). Furthermore, the mean overall survival times in Groups 1 and 2 were 100 and 95 months, respectively, and disease-free survival times were 78 and 74 months, respectively. There were no significant differences between the 2 groups in terms of disease-free and overall survival rates (Figures 1,2). Therefore, the treatment courses selected for these 2 patient populations were well adapted to age and comorbidities.

\section{Discussion}

Previous reports have demonstrated that aging is associated with less aggressive tumor features and higher rates of hormonal responses (Downey et al., 2007; Passage and McCarthy, 2007; Thomas and Leonard, 2009; Syed et al., 2013; Thapa et al., 2013; Wei et al., 2014). In the present study, most (74\%) elderly BC patients were hormone receptor-positive. These data are consistent with previous studies reporting horm one receptor positivity in $60-95 \%$ of elderly BC patients (Molino et al., 2006; Ma et al., 2009).

However, the indolent nature of $\mathrm{BC}$ in elderly patients is partially counterbalanced by larger tumor sizes and more advanced stages at diagnosis in this patient population (Wyld and Reed, 2007; Phua et al., 2010). Accordingly, small tumors ( $\leq 2 \mathrm{~mm}$ ) were found in only $37 \%$ of our elderly patients, compared to $60 \%$ of younger patients. This prevalence of larger tumors at presentation may be explained by a combination of decreased BC awareness, screening, and breast self-examinations in older women (Wyld and Reed, 2007). With regard to lymph node involvement, previous series have reported different results (Molino et al., 2006). Some trials, such as those published by Molino et al. (2006), Gennari et al. (2004), and Daidone et al. (2003), have demonstrated the prevalence of lymph node involvement increases with age, whereas other studies, including those by Fisher et al. (1997), Bonnier et al. (1995), and Thapa et al. (2013) reported a reduction in the incidence of axillary node metastasis in older patients. In the present study, there was no impact of age on lymph node involvement. Such discrepancy among studies may result from the different age groups compared in these studies. Fisher et al.(1997) showed that lymph node involvement, vascular invasion, and axillary metastases increased with age in $\mathrm{BC}$ patients up to 69 years of age; however, these factors decreased dramatically in patients aged $\geq 70$ years. Therefore, the results of our study may be explained by our cutoff value of 65 years falling during this directionality shift. Such disparity between studies may also reflect the strong influence of hormonal changes on BC susceptibility and progression.

In this study, BCS was the most commonly applied surgical procedure, with rates of nearly $65 \%$ in both groups. In the literature, there are heterogeneous reports on the surgical management of elderly patients with BC (Gennari and Audisio, 2008; Hughes et al., 2008; Smith et al., 2009; Thapa et al., 2013). In accordance with our trial, previous data have indicated that $50-80 \%$ of elderly patients undergo BCS (Gennari et al., 2004; Grube et al., 2001). Conversely, some trials have demonstrated 
that mastectomy is the most common type of surgery for elderly patients due to larger tumor sizes; moreover, mastectomy eliminates the need for radiation therapy (Passage and McCarthy, 2007; Ma et al., 2009). Grube et al. (2001) did not find any discrepancy in surgical treatments between older and younger women. Moreover, Tang et al. (2011) analyzed 268 female patients older than 70 years of age and found that $40 \%$ of women with early $\mathrm{BC}$ did not undergo surgical intervention as a primary treatment of their disease. Given the increased risk of relapse, it is recommended that the use of endocrine therapy alone without any surgical intervention should be avoided unless the patient has severe comorbidities that limit life expectancy to $<1$ year (Fentiman, 2013).

The surgical management of the axilla in the elderly has also been controversial. Multiple studies indicate that elderly women receive less aggressive primary therapy, including fever axillary dissections ( esseler and Seton, 1978; August et al., 1994; Wanebo et al., 1997; Downey et al., 2007; Malik et al., 2013; Guth et al., 2013). The perceptions of potential morbidity from surgery and lack of benefit from adjuvant systemic therapy have resulted in omission of axillary surgery in elderly patients (Passage and McCarthy, 2007; Tipples and Robinson, 2009; Tang et al., 2011). However, inadequate axillary treatment has been shown to lead to increased rates of recurrence (Fisher at al., 2002; Passage and McCarthy, 2007). Furthermore, modern surgical and anesthetic techniques allow for breast and axillary surgery to be performed safely in elderly patients (Downey et al., 2007). In the present study, omission of axillary surgery was avoided, and there was no difference between the 2 groups in numbers of patients who underwent axillary surgery. Level I-II axillary dissection in our patients with suspected lymph node involvement did not result in any differences in rates of postoperative complications between both groups.

Although surgical treatment is the mainstay of BC therapy, appropriate application of chemotherapy, radiotherapy, and hormonal therapy may significantly improve survival and reduce local recurrence. Studies have shown that older patients are less likely to receive adjuvant chemo-radiotherapy (Passage and McCarthy, 2007; Yood et al., 2008; Thapa et al., 2013); the major reason for this under-treatment arises from concerns regarding impaired patient fitness due to decreased functional reserve and tolerability, factors secondary to increased age and associated comorbidities.

According to a trial by Harder et al. (2013) investigating barriers to chemotherapy decision-making in elderly BC patients, the main causes of not offering chemotherapy were "other treatments more appropriate" or "benefit too small." As expected, there is an increased frequency in comorbidities with increasing age; $35 \%$ of patients aged 65-79 years have at least 2 comorbid illnesses, as do 70\% of those over 80 years of age (Tipples and Robinson, 2009). Both age and number of comorbid conditions are independently strong indicators of treatment options offered by clinicians. In addition, life expectancy and quality of life also influence treatment decisions in elderly patients. Rather than undergoing a standard curative therapy that may improve survival, many patients may prefer a less aggressive and intensive oncologic treatment so as to improve their quality of life (Molino et al., 2006; Wildiers, 2008; Tang et al., 2011). Therefore, treatment of $\mathrm{BC}$ in elderly patients is multifactorial; treatment strategies should not be based solely on age, but should also take into account the patient's estimated absolute benefit, life expectancy, preference, comorbidities, treatment tolerability, and toxicities.

In the present study, there was a significant trend for fewer patients aged $\geq 65$ years to receive radiotherapy. Moreover, elderly patients were significantly less likely to receive adjuvant chemotherapy than the younger group. In our study, comorbid illnesses were 2-fold more common in older women as compared to the younger group. However, there was no significant age-related difference regarding post-operative complications.

Despite decreased use of radiotherapy and chemoradiotherapy in elderly patients, there were no differences in local control and overall survival between the 2 groups. This may be explained by 2 factors. First, breast cancer in the elderly has more favorable tumor characteristics and outcomes (Passage and McCarthy, 2007). Therefore, if these patients received standard oncologic treatment like their younger counterparts, this may result in better prognoses. The second issue is the effect of $\mathrm{BC}$ on the expected survival of these elderly patients (Diab et al., 2000); importantly, the risk of dying from comorbid conditions often exceeds the risk of cancer recurrence and BC mortality (Satariano and Ragland, 1994).

Compared to younger patient populations, it has been demonstrated that there is a decreased benefit of adjuvant chemotherapy in elderly patients, especially in those with hormone-sensitive tumors (Wildiers, 2008). It has been established that there is an increased frequency of BC hormone receptor positivity in elderly patients, which gives rise to increased implementation of hormonal therapy in these patients. Nevertheless, the absolute effect of radiotherapy after $\mathrm{BCS}$ on local recurrence was less prominent in older women compared with younger women (Wildiers, 2008). Moreover, it is unlikely that radiotherapy will improve survival, as survival in this patient population is influenced more by competing causes of death, such as comorbidities and distant metastases.

Undertreatment of elderly patients, especially in terms of both surgical treatment and chemo-radiotherapy, is a common phenomenon in breast clinics. Despite the limitations of our study, such as a limited number of patients and its retrospective design, the treatment course with less chemo-radiotherapy for elderly BC patients demonstrated a survival rate comparable to those of younger patients. On the other hand, oncologic treatment in accordance with guidelines is necessary to increase the possibility of their likelihood of remaining disease free. The controversy as to whether undertreatment of these patients results in adverse outcomes still exists and further trials are needed to determine the impacts of age on BC and to find optimum treatment strategies in this growing elderly patient populations. 


\section{References}

August DA, Rea T, Sondak VK (1994). Age-related differences in breast cancer treatment. Ann Surg Oncol, 1, 45-52.

Bland KI, Scott-Conner CE, Menck H, Winchester DP (1999). Axillary dissection in breast- conserving surgery for stage I and II breast cancer: a national cancer data base study of patterns of omission and implications for survival. $J \mathrm{Am}$ Coll Surg, 188, 586-95.

Bonnier P, Romain S, Charpin C, et al (1995). Age as a prognostic factor in breast cancer: relationship to pathologic and biologic features. Int J Cancer, 62, 138-44.

Bouchardy C, Rapiti E, Fioretta G, et al (2003). Undertreatment strongly decreases prognosis of breast cancer in elderly women. J Clin Oncol, 21, 3580-7.

Daidone MG, Coradini D, Martelli G, Venerani S (2003). Primary breast cancer in elderly women: biological profile and relation with clinical outcome. Crit Rev Oncol Hematol, 45, 313-25.

Diab SG, Elledge RM, Clark G (2000). Tumor characteristics and clinical outcome of elderly women with breast cancer. J Natl Cancer Inst, 92, 550-6.

Downey L, Livingston R, Stopeck A (2007). Diagnosing and treating breast cancer in elderly women: a call for improved understanding. J Am Geriatr Soc, 55, 1636-44.

Fentiman IS (2013). Management of operable breast cancer in older women. $J$ R Soc Med, 106, 13-8.

Fisher B, Jeong JH, Anderson S, et al (2002). Twenty-fiveyear follow-up of a randomized trial comparing radical mastectomy, total mastectomy, and total mastectomy with irradiation. $N$ Engl J Med, 347, 567-75.

Fisher CJ, Egan MK, Smith P, et al (1997). Histopathology of breast cancer in relation to age. Br J Cancer, 75, 593-6.

Gennari R, Audisio RA (2008). Breast cancer in elderly women. Optimizing the treatment. Breast Cancer Res Treat, 110, 199-209.

Gennari R, Curigliano G, Rotmensz N, et al (2004). Breast carcinoma in elderly women: features of disease presentation, choice of local and systemic treatments compared with younger postmenopausal patients. Cancer, 101, 1302-10.

Grube BJ, Hansen NM, Ye W, Herlong T, Gluliano AE (2001). Surgical management of breast cancer in the elderly patient. Am J Surg, 182, 359-64.

Güth U, Myrick ME, Kandler C, Vetter M (2013). The use of adjuvant endocrine breast cancer therapy in the oldest old. Breast, 22, 863-8.

Harder H, Ballinger R, Langridge C, Ring A, Fallowfield LJ (2013). Adjuvant chemotherapy in elderly women with breast cancer: patients' perspectives on information giving and decision making. Psychooncology, 22, 2729-35.

Hughes S, Barbachano Y, Ashley S, et al (2008). Time trends in the outcome of elderly patients with breast cancer. Breast $J, 14,158-63$.

Kesseler HJ, Seton JZ (1978). The treatment of operable breast cancer in the elderly female. Am J Surg, 135, 664-6.

Ma CD, Zhou Q, Nie XQ, et al (2009). Breast cancer in Chinese elderly women: pathological and clinical characteristics and factors influencing treatment patterns. Crit Rev Oncol Hematol, 71, 258-65.

Malik MK, Tartter PI, Belfer R (2013). Undertreated breast cancer in the elderly. J Cancer Epidemiol, 2013, 893104.

Mohamed NA, Muhamad M (2013). Older women breast cancer survivors: decision making, sources of information and wellness activities in Malaysia. Asian Pac J Cancer Prev, 14, 2043-48.

Molino A, Giovannini M,Auriemma A, et al (2006). Pathological, biological and clinical characteristics, and surgical management, of elderly women with breast cancer. Crit Rev Oncol Hematol, 59, 226-33.

Passage KJ, McCarthy NJ (2007). Critical review of the management of early-stage breast cancer in elderly women. Intern Med J, 37, 181-9.

Phua CE, Bustam AZ, Yip CH, Taib NA (2010). Prognostic factors for elderly breast cancer patients in University Malaya Medical Centre, Malaysia. Asian Pac J Cancer Prev, 11, 1205-11.

Pierga JY, Girre V, Laurence V, et al (2004). Institut Curie Breast Cancer Study Group. Characteristics and outcome of 1755 operable breast cancer in women over 70 years of age. Breast, 13, 369-75.

Rao VS, Garimella V, Hwang M, Drew PJ (2007). Management of early breast cancer in the elderly. Int J Cancer, 120, 1155-60.

Satariano WA, Ragland DR (1994). The effect of comorbidity on 3-year survival of women with primary breast cancer. Ann Intern Med, 120, 104-10.

Siegelmann-Danieli N, Khandelwal V, Wood GC, et al (2006). Breast cancer in elderly women: outcome as affected by age, tumor features, comorbidities, and treatment approach.Clin Breast Cancer, 7, 59-66.

Smith GL, Xu Y, Shih YC, et al (2009). Breast-conserving surgery in older patients with invasive breast cancer: current patterns of treatment across the United States. J Am Coll Surg, 209, 425-33.

Syed BM, Green AR, Paish EC, et al (2013). Biology of primary breast cancer in older women treated by surgery: with correlation with long-term clinical outcome and comparison with their younger counterparts. Br J Cancer, 108, 1042-51.

Tang SW, Parker H, Winterbottom L, et al (2011). Early primary breast cancer in the elderly- pattern of presentation and treatment. Surg Oncol, 20, 7-12.

Thapa B, Singh Y, Sayamil P, et al (2013). Breast cancer in young women from a low risk population in Nepal. Asian Pac J Cancer Prev, 14, 5095-99.

Theriault RL, Litton JK, Mittendorf EA, et al (2011). Age and survival estimates in patients who have node-negative T1ab breast cancer by breast cancer subtype. Clin Breast Cancer, 11, 325-31.

Thomas GA, Leonard RC (2009). Breast cancer in the elderly. Clin Oncol ( $R$ Coll Radiol), 21, 79-80.

Tipples K, Robinson A (2009). Optimizing care of elderly breast cancer patients: a challenging priority. Clin Oncol ( $R$ Coll Radiol), 21, 118-30.

Vrana D, Gatek J, Lukesova L, et al (2013). Omission of adjuvant radiation therapy in elderly patients with low risk breast cancer undergoing breast-conserving surgery - two center experience. Biomed Pap Med Fac Univ Palacky Olomouc Czech Repub, 157, 1-4.

Wanebo HJ, Cole B, Chung M, et al (1997). Is surgical management compromised in elderly patients with breast cancer? Ann Surg, 225, 579-86.

Wei XQ, Li X, Xin XJ, Tong ZS, Zhang S (2014). Clinical features and survival analysis of very young (age $<35)$ breast cancer Patients. Asian Pac J Cancer Prev, 14, 5949-52.

Wildiers $\mathrm{H}$ (2008). Challenges in treating older cancer patients: breast cancer. Ann Oncol, 19,99-103.

Wyld L, Reed M (2007). The role of surgery in the management of older women with breast cancer. Eur J Cancer, 43, 2253-63.

Yellen SB, Cella DF, Leslie WT (1994). Age and clinical decision making in oncology patients. J Natl Cancer Inst, 86, 1766-70.

Yood MU, Owusu C, Buist DS, et al (2008). Mortality impact of lessthan-standard therapy in older breast cancer patients. $J$ Am Coll Surg, 206, 66-75.

Zhao YM, Wang JT, Liu J, et al (2014). Differences between breast cancer patients younger and older than 40 years: mammographic findings. Asian Pac J Cancer Prev, 15, 4929-32 